\title{
Arvedi ESP for High-Quality Hot-Strip Production at Rizhao Steel
}

\author{
Bernd Linzer ${ }^{1, a, ~}{ }^{*}$, Andreas Jungbauer ${ }^{1, b}$ \\ ${ }^{1}$ PRIMETALS Technologies, Turmstraße 44, 4020 Linz, Austria \\ ảBernd.Linzer@primetals.com, ${ }^{\mathrm{b}}$ Andreas.Jungbauer@primetals.com
}

Keywords: Arvedi ESP, Ultra-thin hot rolled strip, cold rolled substitute, AHSS, strip quality

\begin{abstract}
With five Arvedi ESP lines, Rizhao Steel in China is now focusing on the highly attractive local and export markets for high-quality, thin-gauge strip products. The first lines began operations in 2015.

High-strength but lightweight car bodies, ultra-thin structures paired with the highest tensile strength - and all at the lowest production costs. Innovative processes are required in order to fulfil the demands of the car and metals industries. With precise thermo-mechanical rolling and rigorous temperature guidance in the narrowest possible operations windows Arvedi ESP opens the door to producing demanding steel grades in the shortest implementation times and at reduced alloying costs. Low operation costs are also provided by efficient induction heating and the resulting energy savings.

This paper presents the ESP plant setup of Rizhao Steel as well as the training and support program. Additionally the potentials of AHSS production with ESP will be described by referencing the results of the first ESP plant in operation since 2009 at Arvedi Steel, Italy, and the ESP plants of Rizhao steel.
\end{abstract}

\section{Introduction}

The market of flat steels is changing on the one hand to lower average thicknesses and advanced steel design and on the other hand it is still served from classical routes consisting of numerous steps in the production routes. To become more competitive, the desire to cut costs is with every steel producer. The most radical way and highest potential is given by the elimination of as much as possible production steps by directly delivering hot rolled products as cold rolled substitutes.

Developments in the past were going towards this direction, but the full potential can only be exploited since the first fully endless line of Arvedi ESP (Endless Strip Production) went in operation in 2009 in Cremona, Italy. [1] The entire processes and equipment installations from casting of liquid steel to coiling of hot rolled products are brought together at the most compact way within one line and are operated in fully endless mode, until separated in single coil portions by a high speed shear in front of the down coilers as schematically given by the process layout in Figure 1.

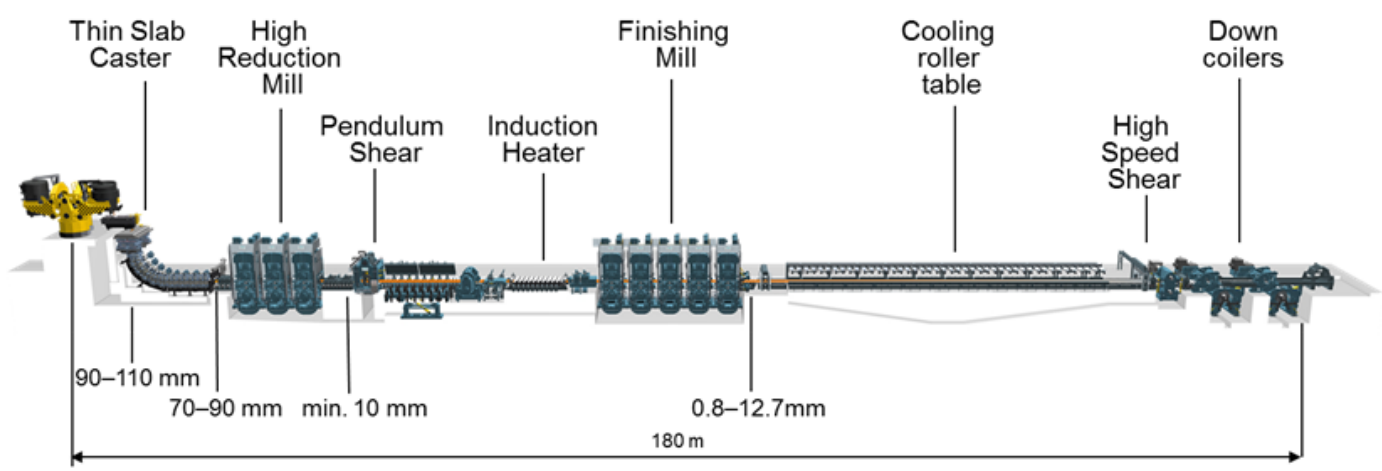

Figure 1. Layout of the Arvedi ESP process 
Recently, the steel producer Rizhao steel in Eastern China selected the Arvedi ESP process to vary its production to high-quality, thin-gauge hot-rolled strip to gain its benefits and a technological lead position in China's saturated steel market. Following an initial investment in mid-2013 for two new Arvedi ESP plants, each with an annual production capacity of 2.55 million tons, a second order was placed with Primetals Technologies for the supply of three additional Arvedi ESP lines that will have a combined rolling capacity of 5.95 million tons of steel per year. In all five lines, strip is rolled to a minimum thickness of $0.8 \mathrm{~mm}$. A wide variety of steel grades will be produced for a broad spectrum of steel products and industrial sectors.

\section{The Potential of Cold Rolled Substitute and New Steel Grade Market}

With Arvedi ESP it is not only possible to produce high quality hot rolled coils but it enables also to partially substitute cold rolled material in just one production step. But how big is the market? Is it worth to invest in a new production facility? For answering this question a short look on worldwide cold rolling production is helpful. Derived from a comparison of worldwide cold rolling facilities the thickness distribution can be roughly estimated as shown in Figure 2, indicating that roughly half of the cold rolling production is above $0.8 \mathrm{~mm}$.

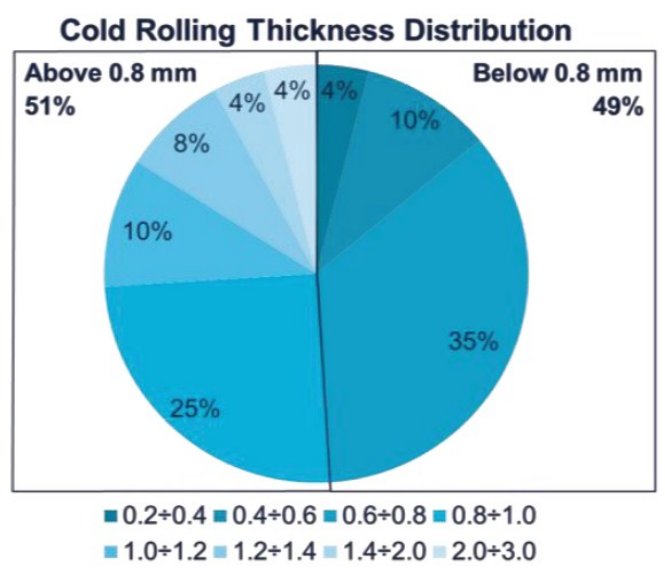

Figure 2. Production statistics of cold rolled material, based on requirements of recent cold rolling projects

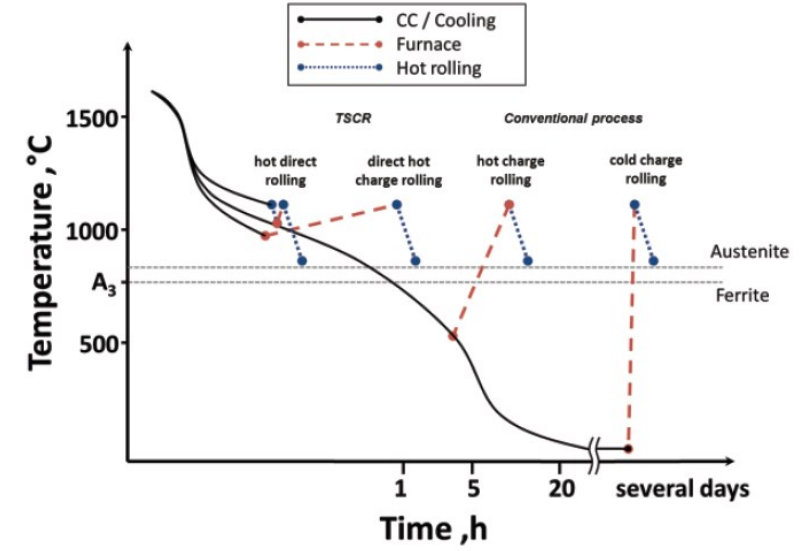

Figure 3. Time/Temperature graphs of different production process types

Of course this statistic differs from country to country and underlies variation of market demand but it shows a clear general trend. For an estimation of the potential market for ESP material as cold rolled substitute following considerations have to be taken into account:

(1) The current worldwide market of cold rolled products is almost 300 million tons (Source: CRU 2014).

This means that additionally to the existing hot coil market there is a non-negligible potential in the cold rolled substitute market for Arvedi ESP technology.

The development of new products and the ongoing evolution of existing steel products, especially driven by innovative customers like the automotive industry are the major drivers pushing towards new steel design concepts. The desire for environmentally sound solutions on an economically feasible cost basis results in large interest to save both, energy and raw materials. These drivers are propelling inventions in light weight construction. During the recent years the steel community witnessed the development and successful market introduction of new steel grades of highly improved formability and increased strength designed for mass applications. The ULSABAVC [2] project showed the potential of newly developed Advanced High Strength Steel grades (AHSS) for automotive body application. AHSS covers dual phase (DP), transformation induced 
plasticity (TRIP), complex phase (CP) and martensitic steels (MART). These grades emerged as a result of the development of first generation AHSS, which are nowadays in full industrial application. A further development lead to extremely high alloyed concepts like the full austenitic TRIP and TWIP (twinning induced plasticity) steels of the second generation AHSS. These products have turned out to be applicable to industrial production only in a very limited number, as several challenges such as castability, appropriate joining technologies and the surface coating topic appeared which still cannot be handled appropriately on a large scale basis. The logical reaction was to reroute towards lower alloying contents and further develop concepts of improved formability for high strength class grades with much leaner chemistry, marked by the group of 3rd generation AHSS.

In order to classify the performance of single steel grades, the ECO index was introduced, which is the product of Ultimate tensile strength and total elongation. Common steel grades of HSLA and first generation AHSS type exhibit round about $20 \mathrm{GPa} \%$. However, the ULSAB project witnessed that this value can be pushed beyond the $30 \mathrm{GPa} \%$ limit for higher alloyed and conventional $3^{\text {rd }}$ generation steel grades, like summarized in [3].

In view of reliable production of advanced steel products of the AHSS family, following means are supporting:

- Process step elimination

- Increase of accuracy

- Increase of process stability and avoidance of unsteady periods

The Arvedi ESP concept provides all these ingredients by bringing the conversion of liquid steel into coils of hot rolled strip to the most stable and compact route possible as given at Figure 3 [4]. The total production time from liquid steel to hot rolled coil is shortened by increasing number continuous single process steps. Especially the time between casting and rolling is significantly influencing the total process time. As the conventional route is based on slab production and cooling of this semi-finished product to room temperature or somehow higher hot charging temperatures around $600^{\circ} \mathrm{C}$, the time between casting and rolling including the reheating time to rolling temperature is typically between many hours or days. The microstructure development along this process chain is dominated by addressing different mechanisms of grain refinement, as it is e.g. linked to recovery/recrystallization, and also the phase transformation during cooling and reheating.

a)
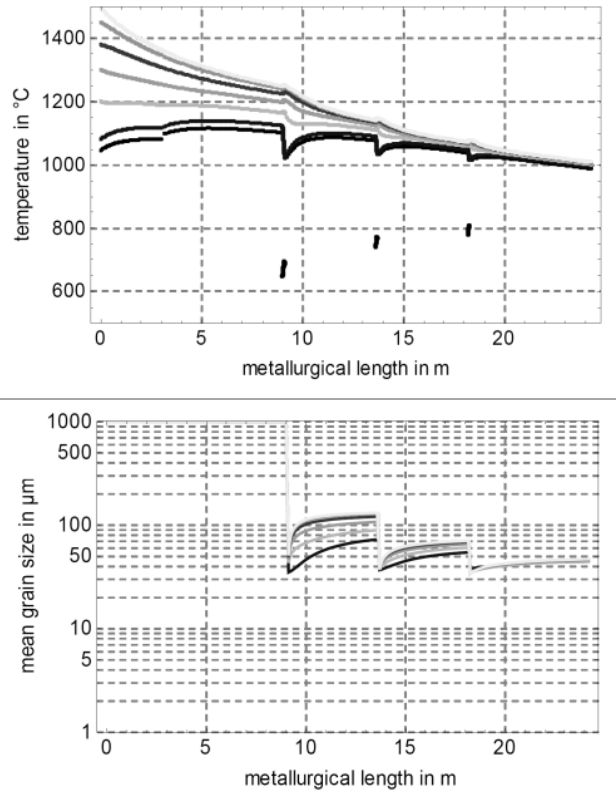

b)
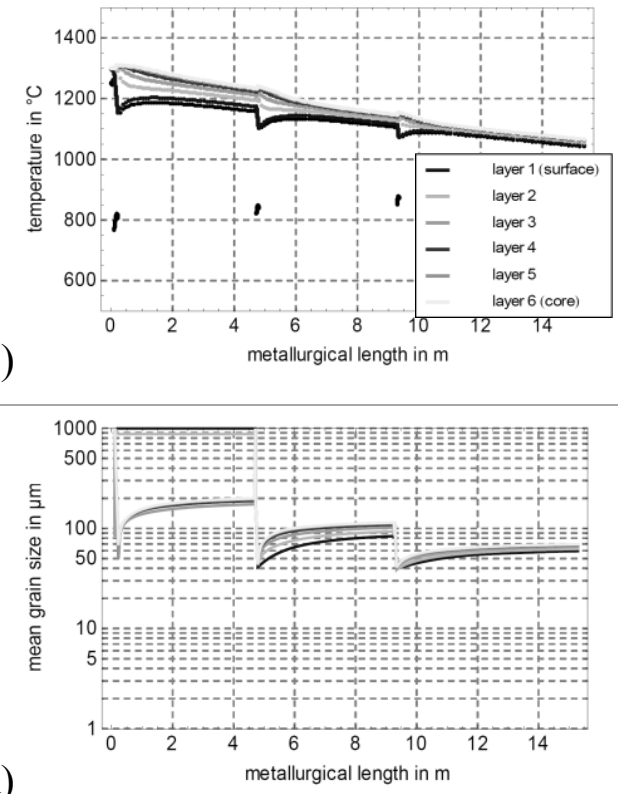

Figure 4. Temperature and mean grain size distribution of S355 along the metallurgical length in the layers after the roughing section with different initial temperature distributions: left $(\mathrm{a}, \mathrm{c})$ inhomogeneous, right (b,d)-homogeneous; for computation an symmetric 11 layer configuration were used 


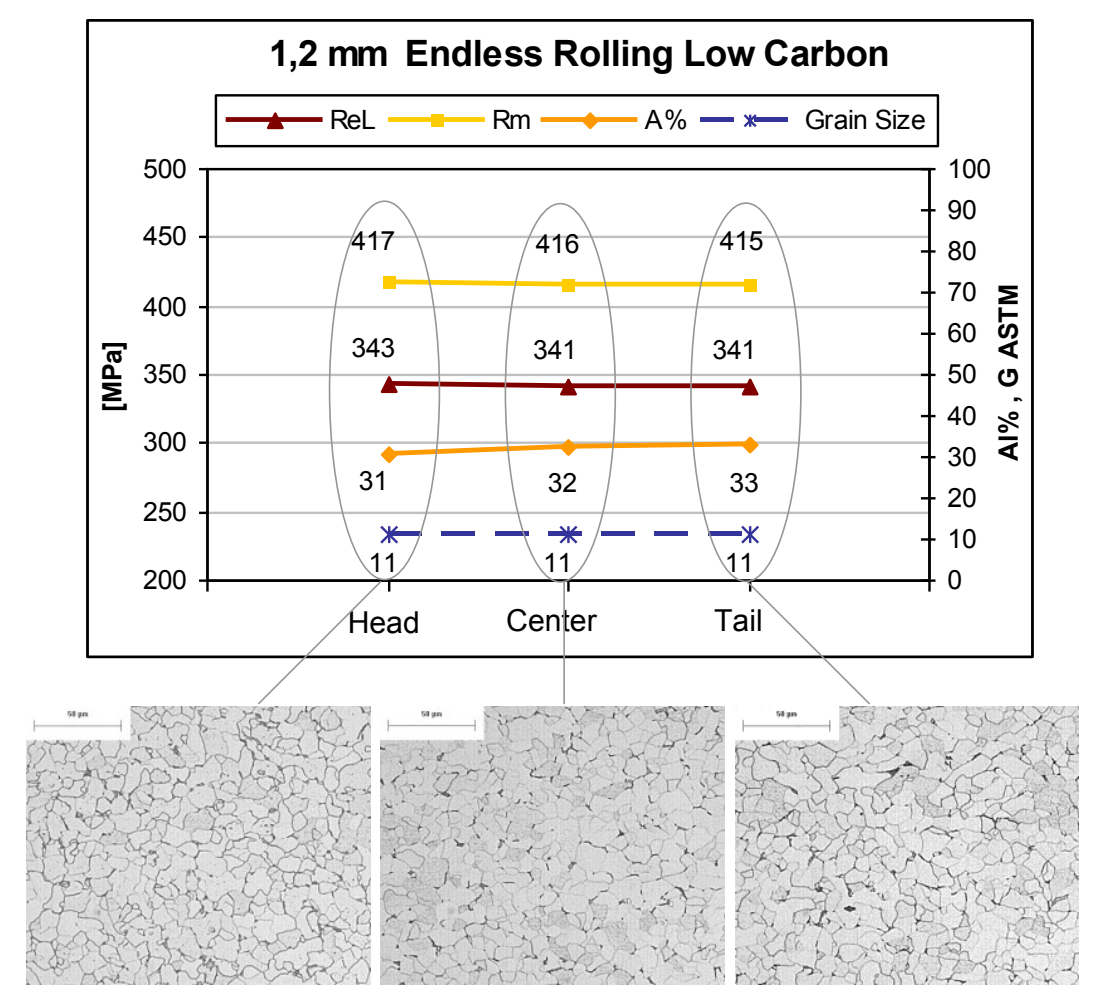

Figure 5. Example of tensile and microstructure properties for 1.2-mm endless rolled low carbon steel

Over the years, a number of combined casting and rolling plants have been built, but the traditional principle remained the same. For while it's true that the slabs do not cool down to room temperature, they are still rolled slab by slab. The time between casting and rolling is reduced to a plenty of minutes. This constitutes a slight improvement, but as there is only one rolling step, the total control freedom is lost.

On ESP the direct link between casting and rolling (reducing the time between casting and rolling to the order of seconds), combined with a short inductive heater and endless operation offers now again the advantage of two separate rolling steps and the possibility for exact temperature control prior to finish rolling. Accordingly, precise microstructure engineering is facilitated, which results in a dramatic reduction in the consumption of expensive alloying elements and opportunities for AHSS grades.

Previous work summarized the microstructure evolution along the Arvedi ESP process, using the example of micro-alloyed steel [5]. The microstructure evolution is dominated by characteristic features of the compact ESP layout. The influence during rough rolling of the so called inverse temperature profile (having a hotter core compared to the surface of the cast product), was described by Schmidtchen et. al. [6]. The results are convincing that the hot core is helping to end up in a more homogenous austenite grain formation after high reduction mill, before entering the inductive heater (Figure 4). During very short reheating durations and final rolling, fine homogeneous microstructures (Figure 5), even thermomechanically treated can be produced due to the stable 2 step rolling concept. A comparison between a series of simulations and measurements from produced material of the Arvedi ESP Masterplant at Cremona showed good confirmation of the strength contribution of fine ferrite grain size, as well as of the precipitation of micro-allying elements, which is done very efficiently during final rolling and strip cooling [7]. Smith et al. showed by their study, that this is also valid for a wide range of possible final strip thicknesses [8].

The ESP process ensures unique stable rolling conditions and constant temperature distributions in every single area of the ESP line not only along a single strip, but also throughout longer periods over entire production sequences. Whereas the finishing exit temperature can be kept constant even 
over several hours including a variety of strip thicknesses with a corresponding standard deviation of less than $2.5^{\circ} \mathrm{C}$ [4]. This process stability does not only apply to temperatures, but also to all other production parameters like strain, strain rates, resulting degree of recrystallized fraction, precipitation and grain growth.

Apart from microstructure evolution, this process stability is also reflected in geometrical quality of the produced steel strip, which already meets cold rolled standards and thus brings the possibility to provide ESP-hot rolled products directly to such market segments and to substitute cold rolled products by bypassing the cold rolling production steps. Figure 6 gives an example of ultra-thin hot strip geometrical data measured inline after finish rolling. This is in sharp contrast to conventional hot rolling where inhomogeneity's are process-inherent, especially due to the transitory state during processing e.g., head and tail region because of thread-in and thread-out effects .

While geometry and uniformity of metallurgical properties were out of question right from the beginning of ESP demonstrations a further quality point turned into focus for the new 5 ESP lines the surface quality. To find the definitive answer, Arvedi ESP material from Cremona had been examined [9]. Several coils went through an automotive production route for pickling, tandem cold rolling mill and finally coating Z100 on the galvanizing line. During cold rolling the flatness was observed carefully starting with 7 I-Units of input material before stand 1 featuring a final flatness of 1 I-Unit after cold rolling stand 5.

The strip was then further checked with the automatic surface inspection system confirming excellent results. The test report was summarized as follows:

- Hot strip geometry very good

- Thickness tolerances very good

- Width very good with only minor deviations

- Very good formability on cold mill, strip was running perfectly

- Perfect flatness after cold rolling and galvanizing

- Practically free from surface defects

Based on the excellent surface quality and the outstanding performance in other requirements of strips for final applications mentioned above, the direct use of the thin gauge hot rolled ESP material instead of cold rolled strip is the only logic consequence. This generates savings of energy for cold rolling, annealing and skin passing.

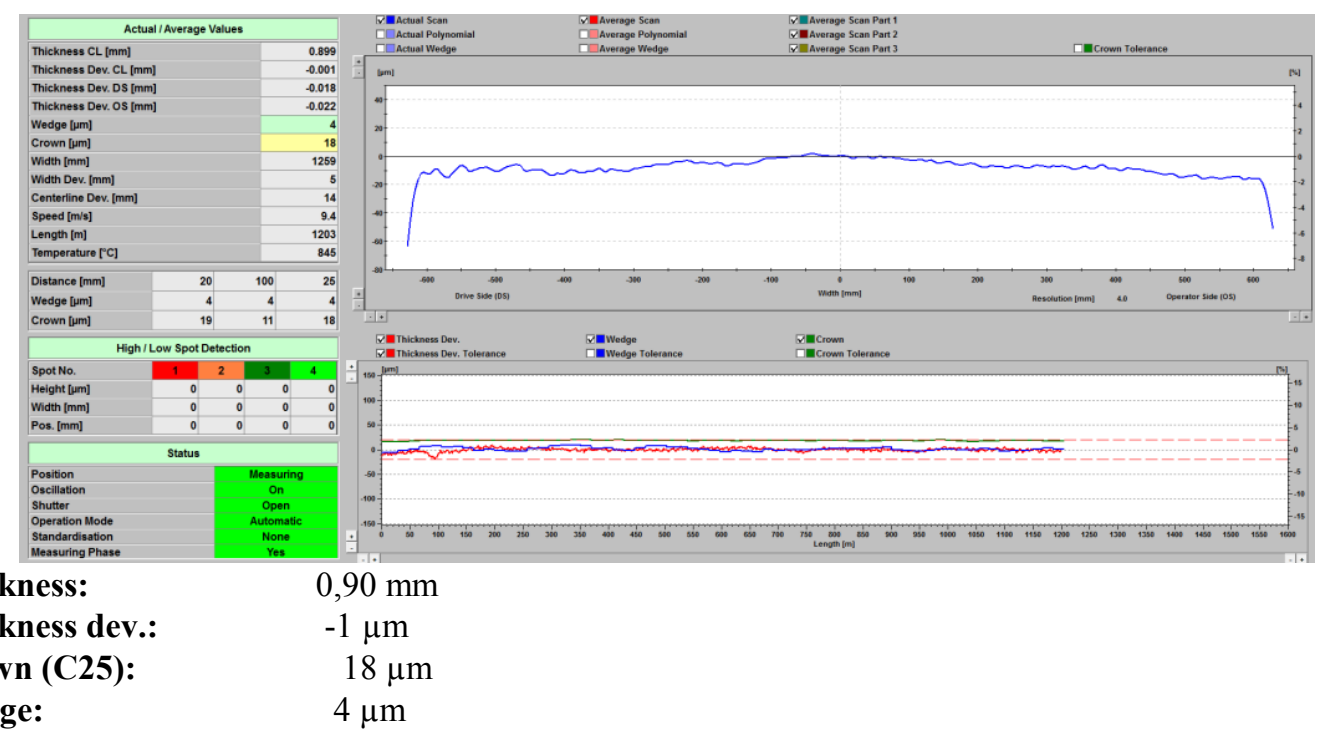

Figure 6. Measurement of geometrical strip data after finish rolling at an ESP line.

For cold rolling Arvedi ESP offers the advantage, starting from a thin hot rolled product with excellent precision. The excellent geometrical constancy from head to tail paired with extremely 
low crown and wedge allows the strip to run in the cold rolling mill smoothly without any fine tuning of the mill. The thinner starting thicknesses of the ESP material is allowing to go for very thin final products, down to gauges such as 0.3 and $0.2 \mathrm{~mm}$ only, by reduced cold rolling investments with a limited number of cold rolling steps, what leads to lower investment and lower processing costs (Figure 7).

\begin{tabular}{|c|c|c|c|c|}
\hline & Arv & di ESP & 3 Stan & PLTCM \\
\hline & $\begin{array}{l}\text { Steel } \\
\text { Grade }\end{array}$ & $\begin{array}{c}\text { Thickness } \\
{[\mathrm{mm}]}\end{array}$ & $\begin{array}{l}\text { Steel } \\
\text { Grade }\end{array}$ & $\begin{array}{c}\text { Thickness } \\
{[\mathrm{mm}]}\end{array}$ \\
\hline & DD12 & $0.80-10.00$ & DD12 & $0.15-2.00$ \\
\hline & $\mathrm{S} 235 \mathrm{JR}$ & $0.85-12.00$ & S235 JR & $0.25-2.00$ \\
\hline & S315 MC & $1.00-12.00$ & S315 MC & $0.30-2.00$ \\
\hline 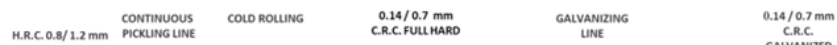 & S355 MC & $1.20-12.00$ & S355 MC & $0.35-2.00$ \\
\hline 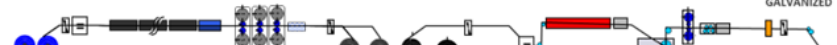 & S420 MC & $1.20-10.00$ & S420 MC & $0.35-2.00$ \\
\hline & S700 MC & $1.80-8.00$ & S700 MC & $0.60-2.00$ \\
\hline & DP 600 & $1.20-5.00$ & DP 600 & $0.35-2.00$ \\
\hline & DP 1000 & $1.50-5.00$ & DP 1000 & $0.45-2.00$ \\
\hline
\end{tabular}

Figure 7. Cold rolling setup in combination with Arvedi ESP and achievable products

The cold reduction might reach up to approx. $70-80 \%$ for soft steel grades, where mechanical properties for drawing as e.g. the Lankford value can be well defined and controlled, as the material of the ESP line convinces by a microstructure comparable to normalized cold rolled material. If applicable, the thin feedstock material can be used to apply only one cold rolling step, whereas for thinnest gauges the well-known two step cold rolling with intermediate annealing for conventional feed stock has to be used. This serves an enormous cost advantage for such products and can also be applied to special products, where the cold rolling is rather expensive due to high brittleness or increased failure rates, such as $\mathrm{Si}$ - Grades.

\section{Replicate the Success of Arvedi ESP in China}

The product mix of the new Chinese plants will comprise low- and ultra-low- carbon steels, medium-carbon steels as well as high-strength low-alloyed (HSLA) and dual-phase steel grades [10].

Quick ramp-up of the new Arvedi ESP lines to their designed production capacity was supported by comprehensive training of Rizhao's operational and maintenance personnel. Basic training comprised theoretical training at Primetals Technologies in Linz and Erlangen for mechanical, electric and automation equipment. This was followed by three weeks of theoretical and practical instruction at the Arvedi ESP plant in Cremona (Figure 8). In a second module with hands-on training, operators were involved with routine operational and maintenance practices for two months at the Arvedi plant in Cremona.

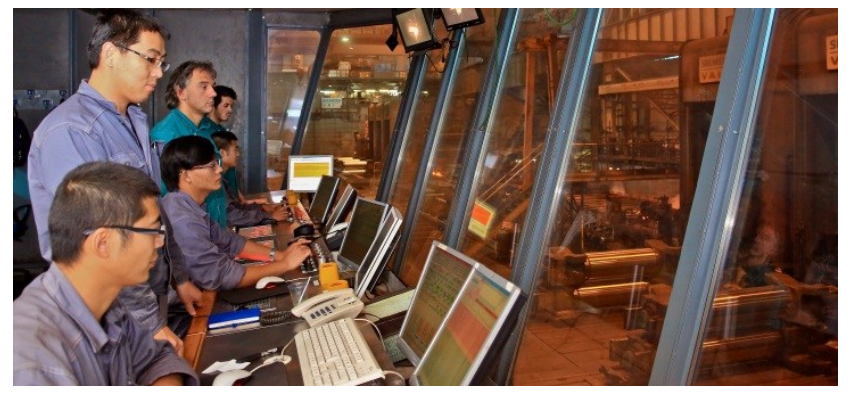

Figure 8. Rizhao steel operators during training at the ESP plant in Cremona, Italy 
During the first year of operation at Rizhao Steel, onsite training and assistance is provided by specialists from Acciaieria Arvedi. The combination of experienced Arvedi experts and well-trained Rizhao personnel ensures reliable plant operations and the production of high-quality final products.

Executing such a complex project in 20 months is a master piece of project management and requires perfect cooperation between Rizhao Steel, main contractor, suppliers and erection company. As the new plants 1-3 are almost identical to the master plant in Cremona many drawings could be sent to the manufacturers within the first weeks of project start. Only this allowed to stick to the very tight time schedule. Also using mainly the same manufacturers as for the plant in Italy contributed to a smooth execution. As manufacturing took mainly place in China, transport times could be limited as well. And finally achieved the erection company under the guidance of Rizhao Steel the nearly impossible to install the whole plant from ground breaking to completion within 12 months.
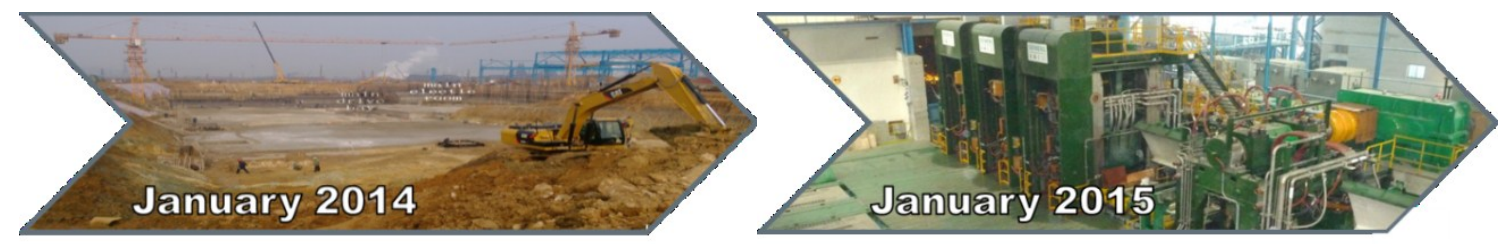

Figure 9. From ground breaking to completion of line 1 within 12 months

In parallel to the commissioning of Line 1, line 2 was already close to finish of the installation, while groundbreaking for plant 3 took place end of 2014 (Figure 9). The first coil of line 3 was meanwhile done after another record breaking short duration of installation on the 26th of September 2015 (Figure 11), six weeks ahead of schedule. Generally the overall project plan foresees a very integrated project execution ending up with the startup of the last plant in 2016 (Figure 10).

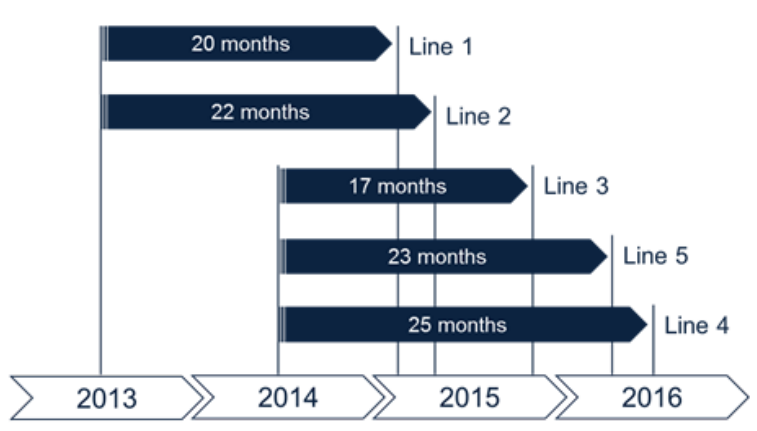

Figure 10. In shortest time to first coil

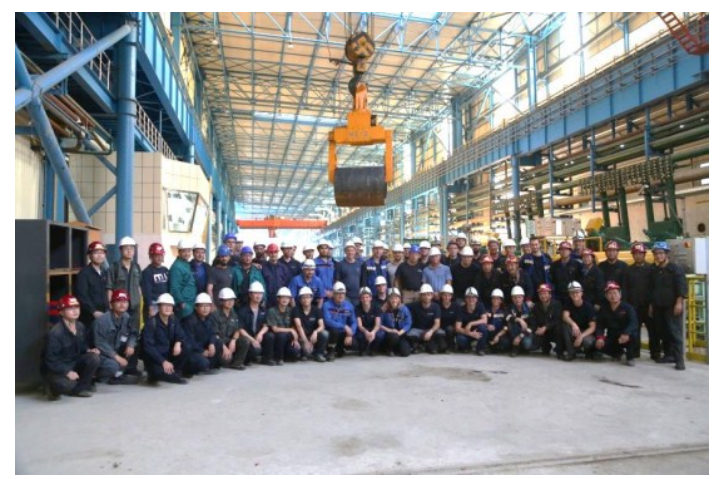

Figure 11. Startup team after producing the first Coil of ESP Line 3 at Rizhao

\section{Summary}

The reliability and stability of the Arvedi ESP process has been well proven in more than five years of operation at Acciaieria Arvedi and now in China. A broad range of advanced steel grades are produced for a wide range of industrial applications.

From quality point of view the final products produced on an Arvedi ESP line are characterized by superior geometrical strip quality and flatness. Outstanding surface quality is proven by a major European automotive supplier who tested the ESP-material on his cold rolling mill. Very high strip homogeneity along its entire length is ensured as in endless operation no strip head or tail end are passing the machine. The cut happens just before the down coiler at the high speed shear and the strip never faces strip threading or tail out procedures as known from conventional batch operated processes. This also contributes to considerably extended work-roll lifetime. Due to the constant 
process parameters and strict strip temperature guidance a reduced consumption of alloys for production of advanced steel grades is noticed. Excellent process stability is not only demonstrated on lowest mold breakout figures and cobble rates but can be seen also on the overall yield of more than $98 \%$ from liquid steel to coil. With consideration to the numerous benefits offered by the Arvedi ESP process, the five new plants in China will provide Rizhao Steel with the basis for longterm business success in China and abroad.

\section{References}

[1] G. Hohenbichler, F. Mazzolari, B. Linzer, A. Jungbauer; Energy Savings by the Arvedi ESP Technology and plant design; Proceedings: METEC InSteelCON 2011, Düsseldorf, Germany, CCD Congress Center Düsseldorf, 27th June - 1st July, 2011

[2] ULSAB-AVC Body Structure Materials, Technical Transfer Dispatch No. 6, May, 2001.

[3] R. Kuziak., R. Kawalla and S. Waengler: Advanced high strength steels for automotive industry; Archives of civil and mechanical engineering, Vol VIII (2008), No. 2

[4] S. Bragin, A. Rimnac, B. Linzer, A. Bianchi, A. Mantova, A. Rizzi; Arvedi ESP process - an ultimate technology connecting casting and rolling in endless mode, 9th International \& 6th European Rolling Conference, Venice / Italy, 10th June 2013

[5] A. Guindani, R. Venturini, A. Rimnac, B. Linzer, Ch. Bernhard, S. Bragin; Thermomechanical processing of low-carbon steels on Arvedi endless strip production lines: Modelling and plant results; TMP 2012, 4th Conference on Thermomechanical Processing of Steels; Sheffield, UK; 2012 Sep. $10-12$

[6] M. Schmidtchen, R. Kawalla1, A. Rimnac; Simulation of Inhomogeneous Materials Evolution in Hot Rolling using a Layer Model; THERMEC 2013, 8th International Conference on advanced materials; Las Vegas, USA; 2-6 Dec. 2013

[7] A. Guindani, R. Venturini, A. Rimnac, B. Linzer, Ch. Bernhard, S. Bragin, Thermomechanical processing of low-carbon steels on Arvedi endless strip production lines: Modelling and plant results; $2^{\text {nd }}$ international Conference on Super-High Strength Steels, Peschiera, Italy; 17-20 Oct. 2010

[8] A. Smith, A. Di Schino, A.Guindani, Suitabuility study of endless strip production technology for fabrication of API grades, 9th International \& 6th European Rolling Conference, Venice / Italy, 10th June 2013

[9] A. Jungbauer, B. Linzer, A. Viehböck, Thin is beautiful - ESP to further develop the cold band substitute market, 2nd ESTAD 2, Düsseldorf/Germany, 14-16. June 2015

[10]A. Jungbauer, B. Linzer, A. Viehböck, Rizhao Steel counts on Arvedi ESP for High-Quality Hot-Strip Production, 2nd ESTAD 2, Düsseldorf/Germany, 14-16. June 2015 